\author{
Pier Antonio Battistella \\ Irene Toldo
}

Published online: 25 October 2006

\section{Headache and recurrent abdominal pains in preschool children}

In a large population-based study, the prevalence of abdominal pains in preschool-age children was found to be high $(39.7 \%)$ [1]. However in this sample the presence of recurrent abdominal pains (RAP), according to Apley's criteria, was much lower $(3.8 \%-11.8 \%)$. It is likely that, using the new, more restricted, criteria of ICHD II [2], the prevalence of RAP will be lower than in previous reports.

Moreover, children with RAP are more likely to experience headache than those without RAP, $27.7 \%$ vs. $14.3 \%$ at 42 months and $55.4 \%$ vs. $37.8 \%$ at 81 months, with a statistically significant difference [1].

The study of Ostkirchen et al. [3] examined the prevalence of primary headache and functional abdominal pains in 555 preschool children assessed by a self-administered questionnaire. In this issue the Authors reported that $85.6 \%$ of the sample suffered from pain, mainly abdominal pains $(33.2 \%)$, often associated with headache $(48.8 \%)$. This high value probably depends on the lack of restricted criteria regarding the pain frequency.

Therefore only $3.6 \%$ of this sample suffered from recurrent headache, with a boy/girl ratio of 10 to 1 [3]. Along with this finding, in outpatient headache sufferers under 6 years of age, a greater male gender prevalence and shorter duration of headache attacks were reported [4].
A recent review on childhood RAP epidemiology showed a prevalence ranging from $0.3 \%$ to $19 \%$ (median $8.4 \%$ ), higher in females [5]. Another study in children with RAP, defined according the Roma II criteria classification system [6], showed that these criteria could improve diagnosis, study and treatment; however further refinement and clarification for symptom duration and frequency may increase diagnostic agreement [7].

An other issue in Ostkirchen's study is that children experiencing combined headache and abdominal pains reach higher headache intensity levels and both types of pain experiences are relevant for children's everyday life because they contribute to an increase of vulnerability [3].

Recently a study exploring recurrent pain symptoms in school children showed that many young subjects suffer from frequently recurring and co-occurring pain symptoms, indicating an urgent need for early preventive and curative programmes [8]. Further studies are needed to assess the prevalence of headache and abdominal pains in an unselected preschool population and to evaluate longitudinally the persistence of these symptoms and the risk of developing recurrent headache in the following ages.

$$
\begin{array}{r}
\text { P.A. Battistella (ख), I. Toldo } \\
\text { Department of Pediatrics } \\
\text { University of Padua } \\
\text { Padova, Italy } \\
\text { e-mail: battist@pediatria.unipd.it }
\end{array}
$$




\section{References}

1. Ramchandani PG, Hotopf M, Sandhu B et al (2005) The epidemiology of recurrent abdominal pain from 2 to 6 years of age: results of a large, population-based study. Pediatrics 116:46-50

2. Headache Classification Subcommittee of the International Headache Society (2004) The International Classification of Headache Disorders, 2nd edition. Cephalalgia 24[Suppl 1]:9-160

3. Ostkirchen GG, Andler F, Hammer F et al (2006) Prevalences of primary headache symptoms at school-entry. A population based epidemiological survey of preschool children in Germany. J Headache Pain 7:331-340
4. Schurman JV, Friesen CA, Danda CE et al (2005) Diagnosing functional abdominal pain with the Rome II criteria: parent, child, and clinician agreement. J Pediatr Gastroenterol Nutr 41:291-295

5. Battistella PA, Fiumana E, Binelli M et al (2006) Primary headaches in preschool age children: clinical study and follow-up in 163 patients. Cephalalgia 26:162-171

6. Chitkara DK, Rawat DJ, Talley NJ (2005) The epidemiology of childhood recurrent abdominal pain in Western countries: a systematic review. Am J Gastroenterol 100:1868-1875
7. Douglas A, Drossman MD with the Rome Multinational working Teams (1999) Rome II. Diagnostic Criteria for the functional Gastrointestinal Disorders. Gut 4:16-26

8. Petersen S, Brulin C, Bergstrom E (2006) Recurrent pain symptoms in young schoolchildren are often multiple. Pain 121:145-150 